\title{
How a motivation programme can affect complex treatment compliance in a rare disease? Results of a questionnaire-based, self-reported study to evaluate "Life Club CF", a programme intended for patients with cystic fibrosis
}

\author{
Marcin Mikos ${ }^{1 *}$, Mikolaj Krzyzanowski ${ }^{2}$, Wojciech Cichy ${ }^{2}$, Pawel Wojtowicz ${ }^{3}$, Anna Sandurska ${ }^{2}$ \\ From 5th European Conference on Rare Diseases (ECRD 2010) \\ Krakow, Poland. 13-15 May 2010
}

\section{Background}

"Life Club CF" is a motivation programme for patients with cystic fibrosis (CF) in Poland, initiated and coordinated by "MATIO" Foundation (Krakow, Poland). Participants collect points for regular specialist outpatient follow-up, adequate nutrition, conducting physical exercise, regular drug intake and reduction in the number of exacerbations. These factors play a major role in complex treatment of CF. Patients may exchange collected points for rewards, such as toys, digital cameras, computers and others. The program was evaluated in a questionnaire-based study.

\section{Aim}

The programme was created to increase treatment compliance through promoting responsible activities among patients with $\mathrm{CF}$ and encouraging regular, multidisciplinary outpatient follow-up. Questionnaire-based study was conducted to evaluate how the programme accomplishes these objectives.

\section{Methods}

A questionnaire consisting of two parts was used: general evaluation ( 2 questions) and activity before and after having signed up in the programme (7 singlechoice questions: rhDNAse intake, body mass control,

*Correspondence: marcin@bajkowe.ne

${ }^{1}$ Head of the Department of Pediatric Gastroenterology and Metabolic Diseases, Franciszek Raszeja Memorial Hospital, Poznan University of Medical Sciences, Poland

Full list of author information is available at the end of the article physical activity and attending outpatient consultations CF physician/pulmonary specialist, physiotherapist, dietician and psychologist). It was completed either by patients or parents/caregivers. Chi-square and FisherFreeman-Halton tests in StatsDirect software package were used to analyse the contingency tables of answers for statistical significance.

\section{Results}

89 questionnaires were returned (53 women and 36 men). The studied group consisted mostly of children with CF; $86.5 \%$ were aged 18 and less (mean age: 13.7 + /- 5.6). Significant differences in frequency of dietician (once a year: $9 \%$ vs. $21.3 \%$ / once in 6 months: $31.5 \%$ vs. 48.3\%; $\mathrm{p}=0.0009$ ), physiotherapist (once in 6 months: $19.1 \%$ vs. $20.2 \%$ / once in 3 months and more often: $21.3 \%$ vs. $39.3 \% ; \mathrm{p}=0.025)$ and psychologist consultations (once a year: $12.4 \%$ vs. $16.9 \%$ / once in 6 months: $18 \%$ vs. $34.8 \%$; $\mathrm{p}=0.027$ ) before and after participating in the programme were detected. Furthermore, significantly more CF patients focus on increasing body weight (57\% vs. $75 \%$; $\mathrm{p}=0.013)$ and regularly perform physical exercise $(19 \%$ vs. $31 \%$; $=0.044)$. No significant differences in rhDNAse intake and frequency of CF clinic consultations were detected.

\section{Conclusion}

Motivation programme "Life Club CF" is a novel and effective method in increasing treatment compliance in important aspects of complex CF care, particularly 
multidisciplinary outpatient follow-up, physiotherapy, nutrition and physical activity.

\section{Author details}

'Head of the Department of Pediatric Gastroenterology and Metabolic

Diseases, Franciszek Raszeja Memorial Hospital, Poznan University of Medical

Sciences, Poland. ${ }^{2}$ Dept. of Pediatric Gastroenterology and Metabolic

Diseases, Szpitalna str. 27/33, 60-572 Poznań, Poland. ${ }^{3}$ Chairman of MATIO

Foundation, ul. Celna 6, 30-507 Kraków Poland.

Published: 19 October 2010

doi:10.1186/1750-1172-5-S1-P7

Cite this article as: Mikos et al.: How a motivation programme can

affect complex treatment compliance in a rare disease? Results of a

questionnaire-based, self-reported study to evaluate "Life Club CF", a

programme intended for patients with cystic fibrosis. Orphanet Journal

of Rare Diseases 2010 5(Suppl 1):P7.

Submit your next manuscript to BioMed Central and take full advantage of:

- Convenient online submission

- Thorough peer review

- No space constraints or color figure charges

- Immediate publication on acceptance

- Inclusion in PubMed, CAS, Scopus and Google Scholar

- Research which is freely available for redistribution

Submit your manuscript at www.biomedcentral.com/submit 